\title{
触 New Disease Reports \\ Leaf spot caused by Neofusicoccum parvum reported on nutmeg in India
}

\author{
V. Jayakumar ${ }^{1,2 *}$, S. Rajalakshmi ${ }^{1}$ and N. Amaresan ${ }^{1}$ \\ ${ }^{1}$ Field Crops Division, Central Agricultural Research Institute, Port Blair- 744101, Andaman \& Nicobar Islands, India ; ${ }^{2}$ Crop \\ Protection Division, Sugarcane Breeding Institute, Coimbatore- 641007, Tamil Nadu, India (present address)
}

*E-mail: jkpath@ rediffmail.com

Received: 27 Nov 2010. Published: 19 Apr 2011. Keywords: Myristica fragrans, foliar disease

Nutmeg (Myristica fragrans, family Myristicaceae) is grown in India for two separate spices, nutmeg and mace. The Andaman and Nicobar group of islands, located between $6-14^{\circ} \mathrm{N}$ and $92-94^{\circ} \mathrm{E}$ in the Bay of Bengal has large areas under cultivation for these spices. In 2008, a survey was conducted in spice cultivation areas for disease incidence. During the survey, moderate to severe incidence of leaf spot disease was observed on nutmeg in the South Andaman group of islands. The symptom initially appeared as small dark brown circular spots later enlarging into irregular spots with a light brown centre (Fig. 1). With severe disease incidence, individual leaves were affected by several spots, giving the appearance of scorching and drying to a branch or full tree. In nutmeg, leaf spot symptoms have previously been reported to be associated with anthracnose caused by Colletotrichum gloeosporioides (Rajeev \& Leela, 2005). However, the prominent symptoms of anthracnose (i.e., production of acervuli, yellow halo and shot hole) were not observed with the newly identified leaf spot.

The pathogen associated with novel leaf spot symptoms produced light to dark brown fluffy mycelium on potato dextrose agar, but sporulation was not observed. On malt extract agar, the culture initially produced white mycelium that turned olivaceous grey after four days, only producing a few spores when the culture plates were exposed to near UV light for five to six days followed by white light for seven days. Conidia produced were hyaline, aseptate and fusiform with average width and length of 5.1 and $18.5 \mu \mathrm{m}$, respectively.The internal transcribed spacer (ITS) region of the fungal DNA was amplified with universal ITS1 and ITS4 primers, sequenced, and submitted to NCBI GenBank (Accession No. FJ919389, isolate FR2). BLAST searches of GenBank using the ITS sequence revealed that this fungus was a member of the genus Neofusicoccum. Isolate FR2 clustered with Neofusicoccum parvum and N. ribis in a phylogenetic tree obtained by the neighbour-joining method in MEGA Version 3.1 (Fig. 2). However, from the report by Pavlic et al. (2007) on differentiation of these two species based on conidial characters, isolate FR2 could be confirmed as $N$. parvum.

Pathogenicity of the newly isolated fungus was tested in five replications on six-month-old nutmeg plants and repeated twice. Mycelial suspension $(1 \mathrm{ml})$ of the fungal isolate was brushed on three intact leaves of each nutmeg plant and incubated for three weeks in a glasshouse at $28^{\circ} \mathrm{C}$ and $70 \%$ relative humidity under natural daylight conditions. Leaves brushed with sterile water served as controls. Similar dark brown symptoms to those found in the field were observed only on treated leaves and the same organism was re-isolated from lesions.Neofusicoccum parvum has been reported as a pathogen causing dieback disease on Syzygium paniculatum (Ploetz et al., 2008), canker of Persea americana (McDonald et al., 2009) and stem canker and dieback on Pyrus pyrifolia (Shen et al., 2010). To our knowledge, this is the first report of leaf spot caused by $N$. parvum and also the first record on nutmeg in India.

\section{References}

McDonald V, Lynch S, Eskalen A, 2009. First report of Neofusicoccum australe, N. luteum, and N. parvum associated with avocado branch canker in California. Plant Disease 93, 967. [doi:10.1094/PDIS-93-9-0967B]

Pavlic D, Slippers B, Coutinho TA, Wingfield MJ, 2007.

Botryosphaeriaceae occurring on native Syzygium cordatum in South

Africa and their potential threat to Eucalyptus. Plant Pathology, 56. 624636. [doi:10.1111/j.1365-3059.2007.01608.x]

Ploetz RC, Pérez-Martínez JM, Palmateer AJ, Cating R, 2008.

Neofusicoccum parvum causes a lethal dieback of Syzygium paniculatum in Florida. Plant Pathology 58, 801

[doi:10.1111/j.1365-3059.2009.02044.x ]

Rajeev P, Leela NK, 2005. Nutmeg. Extension Pamphlet. Indian Institute of Spices Research Publication

[http://www.spices.res.in/pdf/package/nutmeg.pdf].

Shen YM, Chao CH, Liu HL, 2010. First Report of Neofusicoccum parvum associated with stem canker and dieback of Asian pear trees in Taiwan. Plant Disease 94, 1062. [doi:10.1094/PDIS-94-8-1062B]

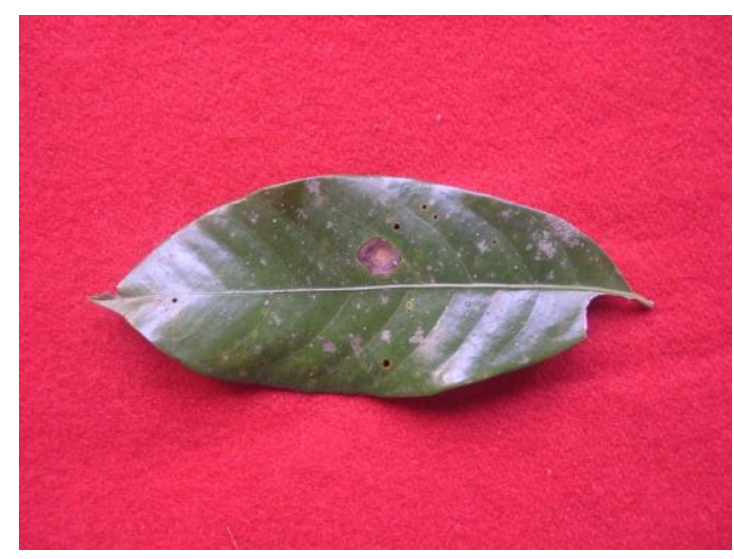

Figure 1

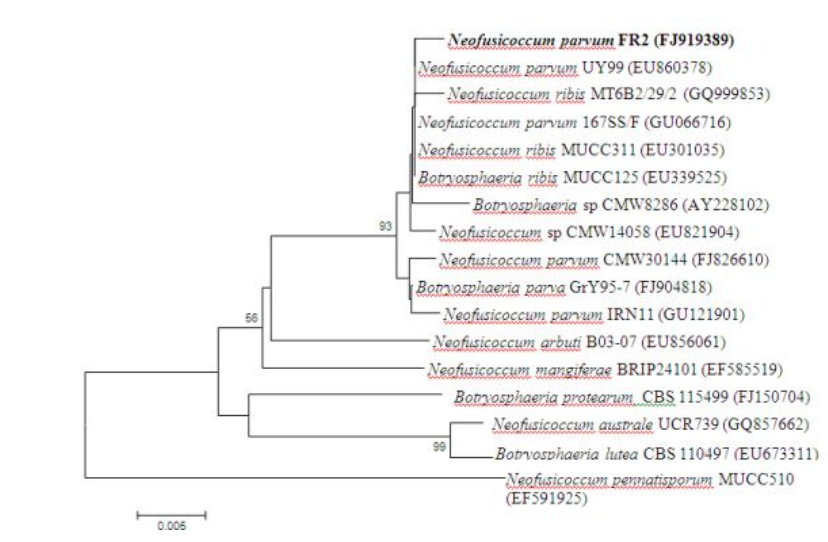

Figure 2

To cite this report: Jayakumar V, Rajalakshmi S, Amaresan N, 2011. Leaf spot caused by Neofusicoccum parvum reported on nutmeg in India. New Disease Reports 23, 19. [doi:10.5197/j.2044-0588.2011.023.019]

(c) 2011 The Authors

This report was published on-line at www.ndrs.org.uk where high quality versions of the figures can be found. 